UDK: 791+811.111:811.163.42

Pregledni rad

Primljeno 19. veljače 2020.

\title{
Transmedijske funkcije filmskih stilskih figura i jezičnih odstupanja od norme $u$ informativnim televizijskim emisijama ${ }^{1}$
}

\author{
dr. sc. SUNČANA TUKSAR \\ Sveučilište Jurja Dobrile u Puli
}

IRENA OSTRIČKI GERBER, mag. bibl. et mag. educ. philol. croat.

doktorska kandidatkinja, Doktorska škola Sveučilišta Josipa Juraja Strossmayera u Osijeku

\begin{abstract}
Govorimo li o komunikološkoj funkciji medija u globalno umreženom društvu, danas je gotovo nezamislivo promišljanje tih funkcija bez problematiziranja njihove transmedijske naravi. Oslanjajući se na sociosemiotičku analizu, rad istražuje funkcije leksičkih odstupanja od jezične norme i to $u$ hrvatskom i engleskom jeziku te televiziji i filmu. Svrha rada je ponajprije pokazati na koji način odstupanja u engleskome jeziku (sleng) u filmu Jima Jarmuscha Noć na zemlji (1991) uspostavljaju kulturološke koncepte te upućuju na usvajanje interkulturalnih kompetencija. Usto, analiza zahvaća i ulogu upotrebe anglicizama u hrvatskome jeziku kako na javnoj televiziji tako i komercijalnim televizijama. Udružene analize upućuju na daljnju sociolingvističku raspravu o potrebi kritičke jezične i vizualne pismenosti u medijima kao i činjenicu da su otkloni od normi iznimno važni pri usvajanju vizualne i medijske pismenosti u globalnoj kulturi. Odnos masovnih medija i jezika nije samo uputa na njihova intrinzično komunikološka svojstva već i jasan podsjetnik na stalnu premreženost društvenog i humanističkog područja.
\end{abstract}

Ključne riječi: transmedijalnost, globalizacija, jezična odstupanja, kultura

1 Dijelovi ovog istraživanja preliminarno su predstavljeni na međunarodnom skupu International Interdisciplinary Scientific Conference Media and Media Culture - Kretanja (Osijek, 2019.) no nisu objavljeni u pripadajućem zborniku. Također, dijelovi teksta koji se odnose na film Noć na zemlji pripadaju disertaciji „Transmedijske i kulturalno-identitetske strategije filmskih reprezentacija“, obranjene 1. travnja 2020. pri Sveučilištu J. J. Strossmayera u Osijeku (Sunčana Tuksar). 


\section{Uvod}

U ovome radu transmedijalnost se prije svega odnosi na premreženost masovnih medija i njihovih jezično-stilskih funkcija, a potom slike i teksta, kako u sociosemiotičkoj, odnosno jezičnoj, tako i u kulturološkoj perspektivi. Pri razmatranju ovih odnosa komunikološki se aspekt nameće kao nužan pristup u suvremenoj teoriji društvenih i humanističkih znanosti. Tome je tako jer je slika postala dominantnim mjestom mišljenja danas i ona gledatelja poziva na kooperativnost u čitanju medija čije su komunikacijske norme, u slučaju ovog rada - jezika, televizije i filma, važne za njezino razumijevanje. Usto, treba imati na umu višestruke uloge medija; od informiranja, posredovanja, odgoja i obrazovanja, socijalizacije, integracije, tematiziranja, kontroliranja, širenja političkog dijaloga ili horizonata, do zabave.

Analiza filmskih reprezentacija, o kojima je ovdje riječ, polazi od pretpostavke da čitatelj film promatra kao komunikološki tekst (Turković, 2008, str. 2012). Nadalje, podrazumijeva tzv. „Zapadnog recipijenta“ - adresata koji može relativno jasno razlučiti instanciju „implicitnog čitatelja te način na koji se poruka medija može shvatiti“"(Gilić, 2007, str. 99). Ovakav tip čitanja filma predstavlja zagovor prema njegovoj transmedijskoj interpretaciji i metadiskurzivnim nadgradnjama. Kao potvrda i primjer ovakve prakse promišljanja poslužit će film Noć na zemlji (Night on Earth, rež. Jim Jarmusch, 1991). Interpretacijom nekoliko odabranih dijaloških filmskih sekvencija u razgovornome jeziku (slengu) propitat će se njihove implicitne funkcije kulturološkog šoka unutar teorije globalizacije (Lewis i Jungman, 1986), kao i da je jezični koncept - sleng - nositelj humorističnog dijaloga. Kompetencije koje će pri doticanju kultura osobito biti na snazi tiču se kulturološkog šoka². Svrha ovakvoga interpretativnog pristupa je svojevrsno promatranje na koji se način dijaloškim stilskim funkcijama stvaraju različita kulturološka značenja. To znači da se ovdje istraživane filmske dijaloške sekvencije promatraju iz očišta sociosemiotičke perspektive i fokusiraju na diskurzivne strategije $u$ funkciji tvorbe kulturoloških koncepata (Kress i van Leeuwen, 1996).

Nadalje, dijalozi u filmovima odlikuju se određenim retoričkim i stilskim postupcima (Turković, 2008; Gilić, 2007; Bordwell, 1986). Stoga se nameće pitanje koja je komunikološka funkcija filmskog dijaloga? To znači da se retorički postupci poput tropa ili književnih figura (Danesi, 2004; Bagić, 2012; Škreb i sur., 1984) ovdje shvaćaju kao mnogo više od „retoričkih alata (Danesi, 2004, str. 118) Već od 70-ih 20. st. teorija ih naziva tropima ili tipovima koji se danas nedvojbeno smatraju manifestacijom kognitivnih procesa. Ovakva podjela retoričkih regulacija na filmu naznačena je isključivo u funkciji sociosemiološke interpretacije i iz tog razloga se one ne naznačuju tipografski nego kontekstualno, odnosno, kako je tumačio Turković, imaju određeni stilski biljeg koji će svojom pozicijom u filmskom izlaganju predstavljati za naraciju strateški značajno mjesto (2008). Na sličan se način ova analiza oslanja na gradnju figure dijaloga u filmu, odnosno njihovu metadiskurzivnu funkciju (2008). Sve u svemu, kako bismo se pomaknuli od klasične filmske teorije i krenuli putem interpretacije, značajno je ime David Bordwell koji podvlači razliku između razumijevanja filma i filmske interpretacije (1985). Pojednostavljeno govoreći, u sociosemiotici riječ je o otkrivanju (skrivenih) značenja. Na konkretnome pak primjeru promatra se način na koji figura humora $\mathrm{u}$ dijalogu oblikuje identitet sudionika razgovora, dakle, sekvencije su analizirane u odnosu na oblikovanje identiteta. U Noći na zemlji dijalog uspostavlja kulturološki dogovor između došljaka i domaćina unutar teorije kulturološkog šoka (Lewis i Jungman, 1986).

2 Termin „kulturološki šok“ reflektira iskustvo koje osoba kao stranac može steći u nekoj okolini. O čovjekovoj sposobnosti da se prilagodi i (ne)mogućnosti da to učini govore i Lewis i Jungman (1986), a samo iskustvo 1960-ih zadobija pažnju antropologa Karleva Oberga, koji je ujedno i skovao taj termin (Lewis i Jungman, 1986, str. 17). 
Ukratko, mediji na recipijente utječu na različite načine, izborom sadržaja, načinom prezentacije toga sadržaja, ali i putem jezičnog izražavanja. Podsjetimo li se općih definicija o jeziku, shvatit ćemo jezik kao sredstvo prenošenja informacija koje kao takvo ima velik utjecaj na recipijente. Govoreći i pišući, mediji se nalaze „u neprestanom procesu izbora“ (Težak, 2002, str. 5). Bogatstvo jezika očituje se u polifunkcionalnosti stilova (Silić i Pranjković, 2005, str. 375), a kada je riječ o medijima i jezičnoj pismenosti, promatra se i analizira tko i na koji način vijest priopćava, što u središte stavlja jezik i stil kojim se izvještava ${ }^{3}$. Razmišljajući o jeziku i stilu medija, Rišner i Glušac granice publicističkog stila „ne smatraju oštrim rubovima, nego osnovama za preplitanje“ te navode dva kuta gledanja na odabir elemenata stila: elementi stila kao poželjna ili nepoželjna kategorija, a ne dobra i loša; slično kao i Ryzner koja smatra da se stil medija može promatrati deskriptivno i preskriptivno, a ona se zalaže za opis i tumačenje, a ne propis i zabranu (Rišner i Glušac, 2011, str. 7).

Ovim se radom nastoji pristupiti transmedijskom iskustvu na razini slikovno-jezičnog iskustva, ali is obzirom na slikovno-kulturološki segment. Naime, kako je u Noći na zemlji riječ o slučajnom susretu likova s društvene margine, u njemu će se ogledati koncept susreta Drugih, odnosno susret između domaćina i došljaka. Došljak je emigrant iz Dresdena, a domaćin crnac iz njujorške četvrti Brooklyn. Konstrukt je slikovno i jezično motiviran kulturološkim reprezentacijama identiteta, dakle, riječ je o skupinama koje se mogu smatrati marginaliziranim manjinama. Unutar teorije globalizacije, mnogi autori propituju intrinzično djelovanje suživota kultura (Gikandi, 2001), odnosno raspravljaju o multikulturalnom građanstvu (Kymlicka, 2003) te se načelno tematizira potreba za kulturalnim pregovorima i/ili dogovorima u globalnom društvu (Wodak, 1989). Globalizacijski jezični procesi neizbježni su zbog činjenice da je engleski jezik nacionalni ili službeni jezik u šezdesetak svjetskih država, a postao je i jezikom filma, glazbe, kulture i medija. Poznavanje engleskog kao svjetskog jezika dio je opće kulture pa tako i odstupanja od njegovog standarda (sleng) ukazuju na određene kulturološke koncepte ${ }^{4}$.

3 Televiziju i danas mnogi jezičari u svojim promišljanjima smatraju centrom većine kućanstava i samim time je ističu u kontekstu njene moći i jezične odgovornosti. Nasuprot stavovima iskazanim u ovome radu, valja napomenuti da odstupanja od norme neki autori smatraju notornim te u tom kontekstu govore o medijskoj (ne)pismenosti kao predmetu razmišljanja i istraživanja samo ponekih znanstvenika zabrinutih za opće stanje krize u medijima pa tako i jezične. Činjenica da će recipijenti „sve što čuju ili pročitaju u medijima uzimati zdravo za gotovo", pokazuje veliki medijski utjecaj, njezinu važnost i moć (Opačić, 2016, str. 9). Badurina s jedne strane stavlja postojanje demokratičnosti u odabiru stila u medijima, a s druge postojanje hiperkorektnosti u izražavanju medija (Badurina, 2001, str. 60). Nadalje, odstupajući od jezične norme, standardnoga hrvatskog jezika, ali i publicističkoga stila, mediji s jedne strane promiču jezičnu nekulturu, stvaraju loše jezične navike i zanemaruju jednu od svojih ključnih uloga, no s druge se strane, odstupanja od norme mogu promatrati kao „vrelo jezične kreativnosti“ (Franić i sur., 2005, str. 247). U tom smislu, o jeziku i stilu medija govori nekoliko autora s različitih stajališta. Autorice Šego, RunjićStoilova i Pandža s pravom su zabrinute zbog utjecaja engleskog na hrvatski jezik, Šego primjećuje snažan utjecaj engleskog jezika na svim njegovim razinama „morfološkoj, leksičkoj, sintaktičkoj i semantičkoj“ (Šego, 2011, str. 57). Fonović-Cijanović i Paronić analiziraju niz sintaktičkih odstupanja uslijed nepoštivanja sintaktičkih normi što narušava jezičnu strukturu. Hudeček i Mihaljević u nizu knjiga i članaka bave se normativnošću i višefunkcionalnošću jezika medija te upozoravaju na veliku odgovornost medija u oblikovanju jezične svijesti recipijenta. Postavljaju pitanje trebaju li novinaru lektori? Ili je dio njihova posla poznavati standardni hrvatski jezik? Opačić u nizu svojih knjiga posvećenih pravilnoj uporabi hrvatskoga jezika, posebice u medijskom prostoru, novonastale tvorevine pseudoanglicizama u hrvatskom jeziku naziva hrengleskim ili bastardnim jezikom, a cijeli postupak nesnalaženja u prijevodu i adaptiranju anglicizama globalizacijskim jezičnim teturanjima i stranputicama, a oba se termina odnose na podnaslove autoričinih knjiga: Hrvatski u zagradama: globalizacijske jezične stranputice (2006) te Hrvatski ni u zagradama: globalizacijska jezična teturanja (2012).

4 S druge strane, ranije spominjani autori načelno smatraju da, kada je riječ o hrvatskome jeziku i medijima općenito, osim velike moći, postoji i velika odgovornost te zakonska i etička obveza televizija i medijskih djelatnika za promicanjem obrazovanja i kulture, a time i jezičnog izražavanja koje poštuje norme standardnoga hrvatskog jezika. Medijske kuće u tom bi kontekstu trebale imati stručne službe za jezik, lektore i korektore te provoditi jezične vježbe. Dok se od emisija zabavnog karaktera mogu očekivati neformalni izrazi, stilski obilježeni leksik i komentari novinara, od informativnih emisija ozbiljnog karaktera očekuje se poštivanje jezičnih normi standardnoga hrvatskog jezika, što propisuje i Zakon o medijima, Zakon o električnim medijima, Zakon o Hrvatskoj radioteleviziji i drugi. Ti se zakoni, nažalost, odnose na javnu televiziju što komercijalne televizije dobro iskorištavaju. 


\section{TEORIJSKO-METODOLOŠKI NACRT}

\section{A) Sociosemiotička interpretativna analiza: analiza diskursa i kulturološkog dijaloga u filmu Noć na zemlji Jima Jarmuscha}

Počevši od komunikacije kao razgovorne forme, postavlja se pitanje što znači razgovarati. Pitanje objašnjavaju Škreb i sur. (1984), koji pružaju ustroj dimenzija razgovora prema sljedećoj podjeli: sudionici (govornici), dijelovi (replike, govor spojeni na koherentan način), faze (početak, središnji dio i završetak), linearni slijed (načelno ograničavanje da se govornici izmjenjuju, preklapanja su moguća, no ako nema ograničavanja u linearnom nizanju dijelova rezultat je monolog ili metež, ali ne i razgovor), kauzativnost (završetak jedne replike u govoru trebao bi rezultirati početkom iduće replike) i svrha (zajednička je svrha održavanje uljudne društvene interakcije na kooperativan način).

Imajući u vidu stilsku i retoričku regulaciju u naznačenim dijalozima u filmu Noć na zemlji Jima Jarmuscha, očituje se vrlo važna uloga figure humora. Humor je figura koja može označiti čovjekovo raspoloženje i koja je povezana s komičnim efektima sreće (Škreb i sur., 1984, str. 253). Lik kao nositelj humora onaj je koji osvještava svoje i tuđe devijacije i u tome „nalazi uveseljenje“. Lik će biti humorističan „ako pokazuje da ima smisao za smiješno te ono što je smiješno zna pokazati drugima“. Unutar figure humora, interpretacija diskurzivnih fragmenata integrira izbor raznih semiotičkih izvora u multimodalni tekst spoj slike i teksta - koji komunicira s gledateljem (Boeriis i Nørgaard, 2013). Analizom se pokazuje da je takav konstrukt utemeljen u figuri humora na intertekstualnoj razini ovoga primjera. Humor je konstruiran u verbalnom i vizualnom dijelu. Shvaća se kao „konstrukt osjećaja“ koji kod gledatelja izaziva „racionalne procese“ (Kress i Van Leeuwen, 1996, str. 64). Djeluje na gledatelja putem multimodalnog, odnosno semiotičkog sustava sačinjenog od stava, gesti, oponašanja, zvuka, pogleda, glasa i verbalnog jezika (Boeriis i Nørgaard, 2013). Humor sudionike u sekvencijama dovodi u situaciju „da u igri ideja otkrivaju s jedne strane, svoj karakter, a s druge razvijaju radnju“ (Škreb i sur., 1984, str. 122).

Analiza ukazuje da figura humora pokreće dijalog. Dijalog je misao koja je upućena drugome, „otvorena misao za druge“ (Škreb i sur., 1984, str. 122). Za Lakoffa i Johnsona komunikacija je razgovorna forma. Kada se pitaju što znači razgovarati, kažu da je to održavanje uljudne društvene interakcije na kooperativan način (2015). U ovome kontekstu, Jewitt govori o konverzaciji kao ugrađenom diskursu koji odgovara „socijalnoj interakciji“ (2016, str. 86). Konverzacija za Jewitt odgovara na pitanje o tome kako akteri kreću od jedne do druge točke događaja te ilustrira na koji način reprezentacija lika oblikuje očekivanja gledatelja (2016, str. 87-90), i to uvijek naglašavanjem konteksta. Drugim riječima, promatra se što se događa u sekvenciji, ili prema riječima Jewitt, u „odabranom isječku“ (engl. selected clip). No, dijalog se odvija i između filmskih sekvencija i gledatelja jer se gledatelju posredstvom njega u podtekstu neprestano još nešto dodatno „poručuje“. Dakle, osim eksplicitnog, u funkciji je i implicitno djelovanje suodnosa teksta i slike na gledatelja.

Stoga se ne promatra samo ono na što su sudionici razgovora usmjereni, nego kako se pritom oni oblikuju te svojom reprezentacijom nose svojevrsnu identitetsku oznaku kojom se obraćaju gledatelju. U filmu Noć na zemlji, vozač taksija je imigrant Helmut, došljak iz Dresdena, a njegov je putnik Njujorčanin, crnac Yo Yo, koji s Manhattana želi stići u Brooklyn. Helmut ne poznaje New York i loš je vozač pa likovi dogovorno mijenjaju mjesta za volanom. Time Yo Yo kao lik doživljava transformaciju iz slučajnog putnika u pristranog suputnika. Helmut pak doživljava pomak unutar teorije kulturološkog šoka, koji se odvija prema fazi participacije u nedomicilnoj kulturi (Lewis i Jungman, 1986). Na mjestu suvozača promatra grad i uči o njemu u razgovoru s Yo Yo. Kulturološka se 
razmjena manifestira putem dijaloga. Prema teoriji kulturološkog šoka, ulaskom u tzv. promatračku fazu očekuje se upijanje novog te pomakom u fazu asimilacije nastoji se uklopiti, odnosno, osoba je spremna prihvatiti i nastoji se uklopiti u kulturu u koju je uronjena (engl. spectator phase). U ovome slučaju dogovor oko razmjene mjesta te učenje slenga putem humorističnog dijaloga dokazuju i pokazuju točnost navedenih tvrdnji.

Slike 1-3: Dogovor oko zamjene mjesta na vozačkoj poziciji je ujedno dogovor u kulturi.
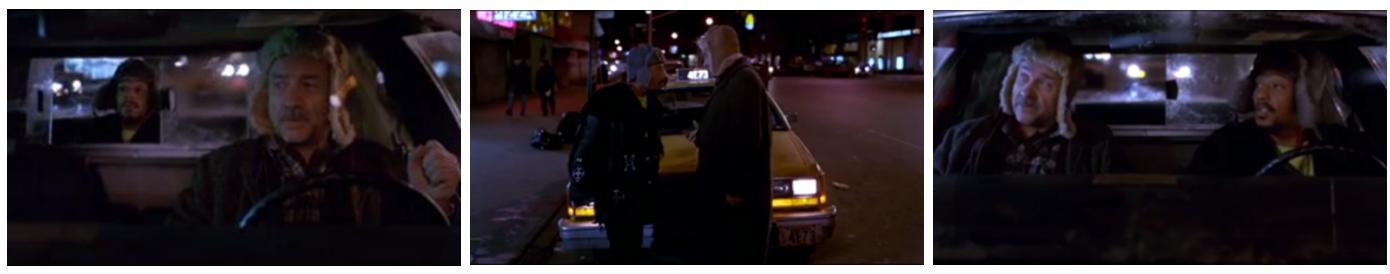

Također, unutar sekvencija snažno djeluje dijaloška forma koja putem humora apostrofira oblikovanje identiteta lika kao kooperativnog, kao i gledatelja. Dinamika dijaloga ukazuje na komplementarnost likova, što znači da se likovi unutar fikcije zajedno razvijaju. Kao rezultat javlja se uranjanje u kulturu gdje se predmnijeva da se kulturološki šok savladava putem iskazanog interesa za domicilnu kulturu. Diskurzivna strategija je poigravanje kulturološkim stereotipima smještajući ih u ugodan promatrački prostor. Stereotipi služe da bi se pokazao Helmutov interes za domicilnu kulturu učenjem Yo Yoova slenga (leksika), razgovorom o imenima te istom ili sličnom odjevnom predmetu. Što se tiče transmedijske razine te suodnosa slike i teksta, u naznačenoj sekvenciji plošni su kadrovi na intradijegetskoj razini popraćeni razgovorom o istim kapama te objašnjavanju Yo Yoova leksika. Pritom Yo Yo koristi „tipični“ sleng čime se referira na stereotipnu „figuru identitetske oznake lika“ (Škreb i sur., 1984, str. 44). Sleng (engl. slang) je šatrovački govor (Škreb i sur., 1984, str. 736). Drugi termin za „šatrovački“ govor je „argo“. Potječe iz Francuske gdje se od kraja 17. stoljeća odnosi „na govor prosjaka, skitnica, lopova i svih onih koji žive na margini društva. Oni stvaraju poseban, tajni jezik, nerazumljiv za neupućene“ (Škreb i sur., 1984, str. 44.). Sleng nije dijalekt. Dijalekt se od standardnog jezika razlikuje fonetski, po rječniku i izrazima i „može biti jedini jezik kojim pojedinac govori“ (1984, str. 44). Pojašnjava se da riječ za sleng kasnije dobije širi smisao te da ga upotrebljavaju ljudi „određene društvene sredine, klase, grupe, profesije“, a naglašavaju da se odnosi i na kulturne slojeve društva.

Ovu tvrdnju potvrđuje i leksikograf John Ayto (1988), koji kaže da je sleng rječnik „in-grupa“; a taj termin koristi i Wodak (1989) te ga općenito tumači isto kao i Ayto, koji ga naziva jezikom bez zadrške, konverzacijskim vokabularom, šarenim leksikom in extremis. Jezik je također jedna od instanci kulturološkog šoka jer vodi jezičnom (ne)sporazumijevanju (Lewis i Jungman, 1986). Leksik, odnosno zbir riječi lika Yo Yo (engl. cool, fresh, jamin, i dr.), pripada slengu - s obzirom na to da Helmut pomoću njega uči i prihvaća inventar njegovih izraza (koji tvore leksik). Lik time ukazuje na pripadanje "in-grupi" jer unutar teorije kulturološkog šoka ovakva razmjena signalizira prihvaćanje razlika u kulturi. 
Kao ilustracija navedenog, slijede dijalozi:

\section{Primjer 1:}

$H:$ What is the hip?

Y: Fresh, jammin, newest, latest...

\section{Primjer 2:}

Y: It's New York. It's cool.

$H$ : It's cold.

Y: No, no, no. It's cool. It's hip. It's happening.

$H$ : Ah, I understand. It's cool...

Y: Right.

\section{Primjer 3:}

H: Goes good!

Y: Yeah, Yeah, goes good...In English we say it's good to go

H: Good to go...it's good...

\section{Primjer 4:}

$H$ : You have the same hat.

Yo-Yo: What? No, no, oh, no, mine is different...

$H:$ Oh, it's the same hat.

Y: Mine is different, man" My is...the newest, latest, fresh!

$H$ : The ear thing here, the same...

Y: No man, my is the hip!

Interpretacija filmskih dijaloga poziva na šira kulturno-teorijska razmatranja; riječ je, dakle, o crncu i imigrantu, a narativ odabrane sekvencije tematizira relativnost susreta između marginalaca unutar etnoskejpa. Ovaj termin upućuje da sekvencije na metadiskurzivnoj ravni obrađuju ideju globalizacije. Američka, dakle domicilna kultura, utjelovljena u likovima Helmuta i Yo Yo konstruirana je kao susretljiva. Kooperativnost likova izgradila je ovu sliku. Na simboličkom planu, također likovi su se usuglasili u sceni u kojoj doslovno mijenjaju mjesta u taksiju (slike 1- 3). O pozicioniranosti na simboličkoj razini, kako tvrdi Wodak (1989), ovime pregovaraju o kulturološkim razlikama. Sve dok je Yo Yo voljan pomoći imigrantu, dotle je imigrant voljan prihvatiti pravila igre, odnosno asimilirati se u kulturu (Lewis i Jungman, 1986).

Naposljetku, što se pak tiče metadiskurzivnih funkcija filmskih dijaloga i humora u naznačenom primjeru, u filmu Noć na zemlji, dijaloške forme humorističnog tipa ukazuju na dogovor odnosno na pregovor o identitetu. U Noći na zemlji razgovara se na kooperativan način i dolazi se do zaključka (Lakoff i Johnson, 2015). Naime, odabrana sekvencija u formi skeča donosi dijaloške razmjene, koja daje humorističan ton. Usporedbom s kulturološkom interpretacijom oblikuje se sljedeća tematska okosnica: izmještavanjem kulturoloških stereotipa iz pregovaračke u dogovornu sferu između došljaka i domaćina ne mogu se zaobići pregovori, odnosno dogovori o kulturi, neophodni u globalnome multikulturalnom društvu (Gikandi, 2001; Kymlicka, 2003) u kojem se neminovno javlja potreba za prilagodbom u raznim fazama tzv. teorije kulturološkog šoka (Lewis i Jungman, 1986). Stoga se konverzacijski narativ promatra kao diskurs koji upućuje na kulturološki konstrukt identiteta unutar teorije globalizacije. 


\section{B) Metoda analize sadržaja: leksička odstupanja u medijima}

Prilikom istraživanja odstupanja od jezične norme u izvještavanju večernjih informativnih emisija dviju televizija, obrađeno je 919 minuta materijala medijskog sadržaja javne, Hrvatske radiotelevizije i privatne, RTL-a u razdoblju od mjesec dana. Na HTV-u je analizirano 27 emisija Dnevnika 3, u prosječnom trajanju od 17 minuta, a na RTL-u 18 emisija RTL Direkta, u prosječnom trajanju od 25 minuta. S obzirom na različito trajanje pojedinačnih emisija, ali i emisija u odnosu na javnu i privatnu televiziju, istražen je podjednak broj minuta medijskog sadržaja, iako ne i jednak broj emisija. Na HTV-u je analizirano ukupno 460 minuta, a na RTL-u 459 minuta. Emisije su praćene i analizirane na službenim mrežnim stranicama HRT-a, ${ }^{5}$ Emisije na zahtjev i RTL-a, ${ }^{6}$ na RTL Sada. Kvalitativnom i kvantitativnom analizom sadržaja obrađeno je 919 minuta medijskog sadržaja gdje su izdvajana i bilježena sva leksička odstupanja i vrste. Prije analize utvrđene su varijable: tuđice, posuđenice, usvojenice i anglicizmi. U dvama su rječnicima stranih riječi ${ }^{7}$ pronađene hrvatske inačice za navedene varijable. Ako nije postojala hrvatska inačica, već objašnjenje, riječi nisu bilježene kao odstupanje. Komparativnom metodom uspoređena su odstupanja i učestalost na HTV-u i RTL-u. Statističkom su metodom obrađeni podatci, a dobiveni rezultata prikazani su opisno u tablicama ${ }^{8}$. Cilj istraživanja bio je navesti primjere, učestalost i vrstu pojavnosti leksičkih odstupanja javne i privatne televizije od norme hrvatskog standardnog jezika te koja televizija prednjači u učestalosti takvih odstupanja.

Leksička odstupanja odabrana su jer je leksik najotvoreniji dio jezičnog sustava u kojem kroz povijest jezika, kao i kod svakog drugog jezika u kontaktu, dolazi do leksičke razmjene. Takva je razmjena prirodna, potrebna pa čak i nužna kako bi zadovoljila potrebe imenovanja novonastalih predmeta i pojava. Velik broj neologizama smatra se ravnopravnim dijelom jezika te takvu pojavu možemo promatrati popunjavanjem praznina pa čak i obogaćivanjem jezika. Otvorenost jezičnog sustava jednako kao i jezično čistunstvo, smatra Muhvić-Dimanovski, pogoduju obogaćivanju jezika i leksičkoj kreativnosti (1998, str. 495-496). Informativne su emisije, pak, izabrane jer novinarskopublicistički stil kao jedan od funkcionalnih stilova podliježe određenim pravilima prema kojima se očekuje poštivanje standardnojezične norme, posebice s obzirom na vrstu emisije i sadržaja.

Redefinirajući klasifikaciju stilova Kovačević i Badurina napominju da se jezik raslojava vertikalno (na govor i pismo) te horizontalno (prema funkcijama) tvoreći tako različite diskurzivne tipove i domene, a takve domene, bile privatne ili javne, specijalizirane, multimedijalne ili literarne, nisu statične tvorbe, već se prožimaju i na taj se način pojedini stilovi opiru svakoj klasifikaciji (2001, str. 19, 30). Takvim prožimanjem počesto dolazi do odstupanja od standardnojezične norme te $u$ pojedinim stilovima dolazi do odmaka u standardološkom shvaćanju stila. Pojedine stilove, smatra

https://www.hrt.hr

6 https://www.rtl.hr

7 Svi su izrazi provjereni u dva rječnika stranih riječi: Klaićevom Rječniku stranih riječi: tuđice i posuđenice te Rječniku stranih riječi autora V. Anića i I. Goldsteina.

8 Navedene se tablice nalaze u Prilogu ovog rada: Rezultati analize javne televizijske kuće HRT očekivano su povoljniji u odnosu na komercijalnu televiziju. Zabilježena su tek 22 odstupanja od leksičke norme standardnog jezika, što je 0,48 puta prosječno puta po emisiji. Riječ je o leksiku kojeg neki autori smatraju neprimjerenom za informativne emisije, tuđicama i posuđenica (akter, lista, komisija), anglicizmima (de luks, PR) ili riječima koje se rabe na neprimjeren način (tretirati ljude). Takve su riječi izdvojene u tablice te su ponuđene njihove hrvatske inačice koje nude rječnici stranih riječi. Za većinu izraza postoji i po nekoliko dobrih alternacija, riječi koje su u skladu s hrvatskom leksičkom normom. Samo nekoliko izraza ne može se zamijeniti izrazom koji se sastoji od jedne riječi, već objašnjenjem od nekoliko riječi (ambijent, egzodus, kvota, pompa, džentlmenski). Ti izrazi, s obzirom da nemaju adekvatnu zamjenu, nisu bilježeni kao odstupanje od leksičke norme. RTL je od leksičke norme očekivano odstupao u većoj mjeri od javne televizije, čak 85 puta, što je 1,88 puta po prosječnoj emisiji. U emisijama se primjećuje puno opušteniji stil izražavanja koji uvelike odstupa od publicističkoga stila te učestalo posuđuje iz razgovornoga, pa čak i književnoumjetničkoga stila, što se vidi po učestaloj uporabi stilskih izražajnih sredstava. Što se pak tiče samoga leksičkog odstupanja, u najvećoj mjeri koriste se tuđice i posuđenice (duplo/dvostruko, faliti/nedostajati, friško/svježe), anglizmi i latinizmi (in/u modi, online/na mreži, super/odlično) te hrvatske riječi u neformalnome, kolokvijalnom obliku (ilegalac/ilegalni imigrant, švicarac/ švicarski franak, krkljanac/gužva). 
Ryznar, nije moguće „omjeravati o društveni i komunikacijski kontekst i vrednovati u odnosu na standardnojezičnu normu“, a „kriterij standardnojezične norme za pojedine stilove može biti poguban“ (2014, str. 65; 2016, str. 106). Među stilove koji se opiru strogoj tradicionalnoj klasifikaciji i koji nemaju jednak odnos prema normi, autorica ubraja razgovorni stil u kojem nije najvažnija njegova „horizontalna funkcionalna uporaba, nego medij ili plan ostvarivanja“ (Ryznar, 2014, str. 65). Jednako tako razgovorni stil vidi i Badurina koja smatra da njegov „ležeran“ status lako prolazi mimo ili kontra norme (Badurina, 2008, str. 115, prema Ryznar, 2016, str. 104). Nadalje, književnoumjetnički ili beletristički stil Bagić opisuje kao „niz autonomnih, naglašeno subjektivnih iskaza“ te ga naziva i posebnim nadstilom koji ne treba proučavati u okviru standardnojezične norme (2003, str. 15-16). Jedan od stilova koji nema jednak odnos prema normi i ne može biti jednako „okovan standardom“ svakako je i novinarsko-publicistički stil analiziran u ovome radu (Ryznar, 2016, str. 103). Na strukturu novinarsko-publicističkoga stila utječe i ispreplitanje multimedijskog i privatnog te dolazi do „pojave anonimnog, umnoženog i kolektivnog autorstva te do povećane fluidnosti tekstualnih margina“, a sve to utječe na strukturu stila (Ryznar, 2016, str. 107). Problemu odstupanja od standardnojezične norme stilistika se može baviti jedino ako izađe iz „željeznog zagrljaja normativistike“, pritom razmišljanja o jezičnoj demokratičnosti i purističkim tendencijama ne moraju nužno biti u opreci (Ryznar, 2016, str. 106-107).

S obzirom na rečeno, možemo zaključiti da su se u ovome radu stilski otkloni od jezične norme u televizijskim informativnim emisijama kao i figura humora u filmu Noć na zemlji problematizirali kao diskurzivne strategije. Dakle, u diskurzivom smislu, medijski se tekst proučavao kao „novo tkivo prošlih citata, dijelova kodova, formula i društvenih uporaba riječi“ ono je što čitatelj stvara svojim aktivnim udjelom i kao takav je mnogoznačan, „prava eksplozija značenja“ (Barthes, 1971 prema Beker, 1988, str. 9-11). Svaki je tekst intertekst te je kao takav pluralan i „teži uočiti tkivo pletiva, isprepletenost kodova, formula i označitelja“ (Barthes, 1971 prema Beker, 1988, str. 13). Različite uloge otklona od norme zasnivaju se, među ostalim, na činjenici da su subjekt i tekst, dakle i jezik, u međusobnoj komunikološkoj interakciji. Subjekt i sam izabire jezik teksta, a ti izbori „vrše funkciju a) organiziranja, b) predstavljanja i c) međudjelovanja“ (Afrić, 2011, str. 20). Zbog toga, važno je uzeti u obzir da kritička vizualna i jezična pismenost može biti povod diskurzivnih promjena u javnom, službenom jeziku javne i komercijalne televizije, ali i u sferi privatnog života. Analiza stilskih figura kao otklona od norme u filmu imala je potpuno drukčiju funkciju, a i učinke na recipijente od istraživanih odstupanja od jezične norme u televizijskim informativnim sadržajima. Diskurzivna analiza jest „analiza jezika u upotrebi“ te je „predana istraživanju onoga što jezik čini“, a „omogućuje ukazivanje na skrivene motivacije iza teksta“ (Afrić, 2011, str. 20-21). Usredotočuje se na društvene aspekte komunikacije i načine na koji se ljude služe jezikom radi postizanja određenih učinaka te „omogućuje pristup ontološkim i epistemološkim pretpostavkama iza projekta, izjava i istraživačkih metoda" (Afrić, 2001, str. 21).

Naposljetku, dvije metode istraživanja u ovome radu pokazuju da su funkcije leksičkih odstupanja u oba medija oblikotvorne kad je riječ o identitetu i kulturi unutar globalizacije, odnosno u globalno umreženom društvu. Naime, u kontekstu globalizacije, metodološki okvir ovog istraživanja obuhvatio je sljedeće: a) sociosemiotičku (nelingvističku) analizu diskursa filmskih reprezentacija na engleskom jeziku te b) semantičko-leksičku analizu medijskog sadržaja tuđica i posuđenica u hrvatskom jeziku. Rezultati kvalitativne analize s jedne strane pokazuju kako uloga figure humora u slengu engleskog jezika u dijalozima filmskih likova u tome mediju može kreirati određene kulturološke koncepte unutar globalne teorije kulturološkog (a). S druge strane, rezultati kvantitativne analize sadržaja ukazuju da odstupanje od jezične norme u informativnim televizijskim emisijama posreduje pri oblikovanju jezične kulture recipijenata (b). Zaključci istraživanja upućuju na to da jezične i stilske 
funkcije figura na različitim medijima poput filma i televizije imaju drukčije uloge, ali i jedne i druge sudjeluju u kreiranju jezičnih i interkulturalnih kompetencija u globalnoj kulturi. Ovakvo istraživanje može se koristiti, ali i dalje proširivati te smatrati općenito neuvriježenim u nastavnoj praksi (engleskog i hrvatskog) jezika gdje se vizualna i medijska pismenost s jedne strane isprepliću, a s druge se medijska pismenost proučava, a ne samo poučava.

\section{Zaključak}

U skladu s interdisciplinarnim transmedijskim pristupom, u ovome se radu donose dva bitna zaključka. Prvi je, filmske reprezentacije svojom vizualnom i verbalnom jukstapozicijom mogu ukazati na potrebu za kulturološkom interpretacijom unutar teorije globalizacije, odnosno kulturološkog šoka. Time se ukazuje na snagu medija jednako kao i na premreženosti slike i jezika u smislu vizualne pismenosti. $S$ druge strane, osim rasprave o metadiskurzivnim svojstvima filmskih reprezentacija, ovim se radom ukazuje da jezik, osim dijaloga, može i treba poslužiti i za kvantitativnu i kvalitativnu analizu sadržaja leksičkih odstupanja od jezične norme i stila. Predložak televizijskih emisija koje se služe anglicizmima, tuđicama i posuđenicama poslužio je kao model medijske pismenosti u tom smislu.

Poveznica semiotike filma i jezika medija na komunikološkoj razini utoliko je jasnija jer se osvrće na razinu značenja koja se postiže analizom dijaloga i humorom kao figurom koja pokreće kulturološke pregovore. Primjeri ovim putem vode do diskusije u smislu vođenja priče prema gledateljevoj pažnji i linijama zaključivanja. Njima dolazimo do elemenata kulturološkog šoka, odnosno u Noć na zemlji izmještanjem kulturoloških stereotipa iz pregovaračke u dogovornu sferu unutar kulturološkog šoka. Ako je uvjet za dogovor o kulturi taj da se jasno razgraniči tko je došljak, a tko domaćin, to je u filmu Noć na zemlji dogovoreno. Humoristična stilizacija lika Yo Yo, crnca iz Brooklyna sugerira da su minimalna propitivanja u vezi kulturoloških razlika, odnosno tko bi od koga trebao prihvatiti elemente čije kulture. Većinom se podrazumijeva da će to učiniti došljak, imigrant iz Dresdena, što on spremno i čini i time pokazuje spremnost da se asimilira u kulturu i/ili in-grupu.

Što se pak tiče jezika i analize medijskog diskursa, takva je analiza neophodna jer bez sustava kontrasta nema formalne „razlike“ iz koje zapravo može izrasti i proizlazi proces signifikacije. Što se tiče leksičkih odstupanja, ona se događaju zbog niza mogućih razloga. Neki od njih mogu se očitovati u činjenici da je jezik živ organizam, a njegov leksik najotvoreniji i najpodložniji sustav s dugom tradicijom jezičnog posuđivanja kroz vrijeme i prostor. Drugi se pak može prepoznati u utjecaju globalizacijskih procesa na jezik općenito, pa tako i medijski. Naime, upravo proces globalizacije utječe na nove jezične procese dvaju jezika, hrvatskog i engleskog. Jezici su i prije bili u kontaktu, no, promjene su nastajale sporo i na površinskoj razini, dajući tako vremena jeziku i govornicima na prilagodbu. Strukturalna temeljna razina prirode jezika bila je sačuvana jer su se promjene događale kontrolirano. Govoreći o promjenama općenito, a promišljajući o jeziku medija, napomenuli smo da neki autori, primjerice Opačić, tvrde da se izreka polako, ali sigurno može promijeniti u „sigurno, ali ne polako, nego upravo galopirajući“ (Opačić, 2016, str. 9). Baš takvim galopirajućim i nimalo suptilnim tempom nastaju nove riječi koje nisu nužno neprilagođene u svojoj težnji da sustignu potrebu za označivanjem novih pojava. Zahvaljujući globalnoj umreženosti i participaciji, takve riječi vrlo brzo ulaze i u široku uporabu medija pa posljedično tome i cijelog društva. Nadalje, treći se razlozi očituju u prepoznavanju prilike medija da ozbiljni informativni sadržaj predstave jezikom bližim jeziku prosječnog recipijenta, da pretvore ozbiljniji sadržaj informativnih emisija u infotainment i na taj način povećaju gledanost. Na taj način komercijalne televizije postaju financijski učinkovitije i isplativije, a javne pokušavaju ići u korak s komercijalnim, što danas ne bi nužno više trebalo biti obrnuto. Naposljetku, iako je jezik oduvijek bio važna sastavnica hrvatskog identiteta, 
kada je riječ o jezičnom posuđivanju, globalizacijskim procesima u jeziku koji dovode do nastanka tuđica općenito, anglicizama i pseudoanglicizama, njih je nemoguće spriječiti jer „jezici su, poput kultura, rijetko samodovoljni“" (Sapir, 2013, str. 148).

Dakle, kada objedinimo raspravu o dijalogu i slengu unutar teorije globalizacije, ona je u interdisciplinarnom smislu relevantna za oba jezika, hrvatski i engleski, osobito uz pretpostavku da su jezične norme u širem smislu pouzdano prihvaćene pa se samim tim podrazumijevanju i njihova odstupanja. U metodološkom smislu, obje analitičko-interpretativne metode ukazuju na potrebu za usvajanjem i razumijevanjem komunikološke razine na kojoj nastaju kulturološki koncepti otvoreni za daljnju interpretaciju u smislu interkulturalnih kompetencija, medijske i vizualne pismenosti, a sami time i s potencijalnim edukativnim nakanama u praksi. Prvenstveno se obraća djelatnicima u medijima, novinarima, ali i šire, akademskoj zajednici koja se bavi raspravama o jeziku, medijima i kulturi.

\section{Literatura}

Afrić, V. (2011). Uvod. Povijesni razvoj i teorijsko utemeljenje diskurzivne analize. U: A. Leburić i sur (ur.) Diskurzivna analiza, Metodološke teme. Redak.

Anić, V. (2011). Rječnik hrvatskoga jezika (treće prošireno izdanje). Novi liber.

Anić, V. i Goldstein, I. (2000). Rječnik stranih riječi (drugo izdanje). Novi liber.

Anić, V. i Goldstein, I. (2007). Rječnik stranih riječi. Novi liber.

Ayto, J. (1988). Dictionary of Slang Dictionary. Oxford: OUP.

Badurina, L. (2007). Jezično raslojavanje i tipovi diskursa. U: K. Bagić (ur.) Jezik književnosti $i$ književni ideologemi: zbornik radova 35. seminara Zagrebačke slavističke škole (str. 11-20). Zagrebačka slavistička škola.

Bagić, K. (2012). Rječnik stilskih figura. Školska knjiga.

Bagić, K. (2003). Treba li pisati kako dobri pisci pišu. Disput.

Beker, M. (1988). Tekst/intertekst. U: Z. Maković i sur. (ur.) Intertekstualnost \& intermedijalnost (str. 9-20). Zavod za znanost o književnosti.

Blagus Bartolec, G. (2015). Vatreni, Kauboji i Stara dama. Metafora i metonimija u medijima, Hrvatski jezik, 2(1) 6-9.

Boeriis, M. i Nørgaard, N. (2013). The multimodal construal of humour and intertextuality in Tele2's Small Bill/Big Bill campaign. Campobasso: Palladino.

Bordwell, D. (1985). Narration in the Fiction Film. The University of Wisconsin.

Cifrić, I. (2008). Imperij ili zajednica?. Društvena istraživanja, 17(4-5)(96-97), 773-797.

Cvikić, L. (2009). Hrvatski - mali, ali zavičajni jezik. U: B. Kryzan-Stanojević (ur.) Lice i naličje jezične globalizacije. Srednja Europa.

Demokracija i demokratizacija (2013). (ur. A. Milardović i N. Jožanec). Pan liber; Institut za europske i globalizacijske studije.

Danesi, M. (2004). Messages, Signs, and Meanings: A Basic Textbook in Semiotics and Communication, Canadian Scholar's Press Inc.

Frančić, A., Hudeček, L. i Mihaljević, M. (2005). Normativnost i višefunkcionalnost u hrvatskome standardnom jeziku. Hrvatska sveučilišna naklada. 
Gikandi, S. (2001). Globalization and the Claims of Postcoloniality. The South Atlantic Quaterly, 100(3), 627-658.

Gilić, N. (2007). Uvod u teoriju filmske priče. Školska knjiga.

Granić, J. (2006). Novi „razrađeni“ mediji i „ograničeni“ kodovi. U: J. Granić (ur.) Jezik i mediji jedan jezik: više svjetova (str. 267-278). Hrvatsko društvo za primijenjenu lingvistiku.

Granić, J. (2007). Jezik i identitet: zbornik. Hrvatsko društvo za primijenjenu lingvistiku.

Hagege, C. (2005). Zaustaviti izumiranje jezika. Disput.

Hrvatski pravopis (2013). (gl. ur. Ž. Jozić.). Institut za hrvatski jezik i jezikoslovlje.

Hall, S. (2005). Kulturni identitet i filmska reprezentacija. Matica Hrvatska; Kolo.

Harpham, G. (1987). The Ascetic Imperative in Culture and Criticism. University of Chicago Press.

Hudeček, L. i Mihaljević, M. (2013). Jezik medija: publicistički funkcionalni stil. Hrvatska sveučilišna naklada.

Hudeček, L. i Mihaljević, M. (2010). Odgovornost novinara za jezičnu kulturu (Treba li novinaru lektor?). U: D. Labaš (ur.) Mediji i društvena odgovornost (str. 271-283). Hrvatski studiji.

Jenkins, H. (2006). Convergence Culture: Where Old and New Media Collide. New York University Press. Jewitt, C. i sur. (2016). Introducing Multimodality. Routledge.

Kovačević, M. i Badurina, L. (2001). Raslojavanje jezične stvarnosti. Izdavački centar Rijeka.

Kress, G. i Van Leeuwen, Th. (1996). Reading Images: The Grammar of Visual Design. Routledge.

Kymlicka, W. (2003). Multikulturalno građanstvo. Naklada Jesenski i Turk.

Klaić, B. (1990). Rječnik stranih riječi: tuđice i posuđenice. Nakladni zavod MH.

Kryzan-Stanojević, B. (2009) Mali i manji između integracije i globalizacije, Lice i naličje jezične globalizacije (ur. Barbara Kryzan-Stanojević). Srednja Europa.

Labaš, D. (2011). Hrvatski novinari i mediji: od doba „beskućništva“ do doba „okućivanja", U: Komunikacija i mediji u krizi: zbornik radova znanstvenog kolokvija s međunarodnim sudjelovanjem. Hrvatski studiji.

Lakoff, G. i Johnson, M. (2015). Metafore koje život znače. Disput.

Lewis, T. J. i Jungman R. E. (ur.), (1986). On Being Foreign: Culture Shock in Short Fiction. An International Anthology Intercultural Press, Inc.

Matasović, R. (2005). Jezična raznolikost svijeta: podrijetlo, razvitak, izgledi. Algoritam.

Milardović, A. (2004). Pod globalnim šeširom: društva i države u tranziciji i globalizaciji: ogledi iz politologije i sociologije politike. Centar za politološka istraživanja.

Muhvić-Dimanovski, V. (1998). Neologizmi na razmeđi jezične otvorenosti i jezičnog purizma, Filologija, 30-31, 495-499.

Nikolić-Hoyt, A. (2007). Uloga popularnih novih medija u jeziku globalnih tinejdžera, U: J. Granić (ur.) Jezik $i$ identitet. Hrvatsko društvo za primijenjenu lingvistiku 495-502.

Opačić, N. (2009). Globalizacija i mali narodi, u: Lice i naličje jezične globalizacije (ur. Barbara Kryzan-Stanojević). Srednja Europa.

Opačić, N. (2012). Hrvatski u zagradama: globalizacijska jezična teturanja. Hrvatska sveučilišna naklada. 
Opačić, N. (2016). Osjenčane riječi. Matica hrvatska.

Rišner, V. i Glušac, M. (2011). Kroz mijene i dodire publicističkoga stil. Zrcalo sadašnjosti.

Runjić-Stoilova, A. i Pandža, A. (2010). Prilagodba anglizama u govoru na hrvatskim televizijama. Časopis za hrvatske studije, 6(1) 229-240.

Ryznar, A. (2016). Koliko je danas funkcionalna funkcionalna stilistika. Croatica: časopis za hrvatski jezik, književnost i jezik, 40(60), 101-110.

Ryznar, A. (2014). Interdiskurzivnost: stilistički prilog teoriji književnog diskursa. Umjetnost riječi, 58(1), 55-74.

Sapir, E. (2013). Jezik: uvod u istraživanje govora. Institut za hrvatski jezik i jezikoslovlje.

Stiglitz, J. (2004). Globalizacija i dvojbe koje izaziva. Algoritam.

Šego, J. (2010). Obrazovanje za medije. U: D. Labaš (ur.) Mediji i društvena odgovornost. Hrvatski studiji. Škreb i sur. (1984). Rječnik književnih termina. Nolit.

Težak, S. (2002). Između jezika i stila. Tipex.

Turković, H. (2008). Retoričke regulacije. AGM.

Turković, H. (2012). Teorija filma, treće dopunjeno izdanje. Meandar Media.

Wodak, R. (ur.), (2013). Critical Discourse Analysis: Volume I: Concepts, History, Theory. Sage.

Wodak, R. (ur.), (1989). Language, Power and Ideology. Benjamins.

\section{Filmografija:}

Noć na zemlji (rež. Jim Jarmusch, 1991). 


\section{Mrežni izvori:}

http://www.rtl.hr/rtl-sada/magazini/rtl-danas/71795/ http://www.rtl.hr/rtl-sada/magazini/rtl-danas/71705/ http://www.sada.rtl.hr/info-i-magazini/rtl-direkt/7772 http://www.sada.rtl.hr/info-i-magazini/rtl-direkt/77484/ http://www.sada.rtl.hr/info-i-magazini/rtl-direkt/77267/ http://www.sada.rtl.hr/info-i-magazini/rtl-direkt/77017/ http://www.sada.rtl.hr/info-i-magazini/rtl-direkt/76922/ http://www.sada.rtl.hr/info-i-magazini/rtl-direkt/76902/ http://www.sada.rtl.hr/info-i-magazini/rtl-direkt/76794/ http://www.sada.rtl.hr/info-i-magazini/rtl-direkt/76580/ http://www.sada.rtl.hr/info-i-magazini/rtl-direkt/76478/ http://www.sada.rtl.hr/info-i-magazini/rtl-direkt/76399/ http://www.sada.rtl.hr/info-i-magazini/rtl-direkt/76478/ http://www.sada.rtl.hr/info-i-magazini/rtl-direkt/76399/ http://www.sada.rtl.hr/info-i-magazini/rtl-direkt/76336/ http://www.sada.rtl.hr/info-i-magazini/rtl-direkt/76580/ http://www.hrt.hr/enz/dnevnik-3/294845/ http://www.hrt.hr/enz/dnevnik-3/295076/ http://www.hrt.hr/enz/dnevnik-3/295291/ http://www.hrt.hr/enz/dnevnik-3/295379/ http://www.hrt.hr/enz/dnevnik-3/295425/ http://www.hrt.hr/enz/dnevnik-3/295547/ http://www.hrt.hr/enz/dnevnik-3/295636/ http://www.hrt.hr/enz/dnevnik-3/295760/ http://www.hrt.hr/enz/dnevnik-3/295863/ http://www.hrt.hr/enz/dnevnik-3/296308/ http://www.hrt.hr/enz/dnevnik-3/296433/ http://www.hrt.hr/enz/dnevnik-3/296648/ http://www.hrt.hr/enz/dnevnik-3/297102/ http://www.hrt.hr/enz/dnevnik-3/297189/ http://www.hrt.hr/enz/dnevnik-3/297317/ http://www.hrt.hr/enz/dnevnik-3/297467/ http://www.hrt.hr/enz/dnevnik-3/297884/ http://www.hrt.hr/enz/dnevnik-3/298134/ http://www.hrt.hr/enz/dnevnik-3/295972/ http://www.hrt.hr/enz/dnevnik-3/296526/ http://www.hrt.hr/enz/dnevnik-3/296907/ http://www.hrt.hr/enz/dnevnik-3/296990/ http://www.hrt.hr/enz/dnevnik-3/297604/ http://www.hrt.hr/enz/dnevnik/297341/ (pristupljeno 31. svibnja 2020.) 


\section{Prilozi}

Tablica 1. HTV: Leksička odstupanja: tuđice, posuđenice, usvojenice i anglicizmi

\begin{tabular}{|c|c|}
\hline HTV, Dnevnik & \\
\hline akter & sudionik (Anić, Goldstein, 2000, 62) \\
\hline ambijent & atmosfera koja vlada; ukupnost predmeta; životna sredina (Anić, Goldstein, 2000, 78) \\
\hline ceremonija & obred (Anić, Goldstein, 2000, 225) \\
\hline de luks & prvoklasan, luksuzan (Anić, Goldstein, 2000, 275) \\
\hline džentlmenski & koji se odlikuje plemenitošću, uglađenošću (Anić, Goldstein, 2000, 341) \\
\hline egzodus & odlazak velikog broja ljudi iz kojeg kraja (Anić, Goldstein, 2000, 356) \\
\hline favorit & ljubimac; miljenik; kojem se daju najveći izgledi za pobjedu (Anić, Goldstein, 2000, 419) \\
\hline fokus & centar, središe interesa, zanimanja (Anić, Goldstein, 2000, 445) \\
\hline fotelja & naslonjač (Anić, Goldstein, 2000, 451) \\
\hline gumenjak & gumeni čamac \\
\hline humanitarac & onaj koji sudjeluje u humanitarnoj djelatnosti (Anić, Goldstein, 2000, 571) \\
\hline ilegalac & ilegalni imigrant \\
\hline klinci & djeca \\
\hline komisija & privremeno ili stalno vijeće; povjerenstvo (Klaić, 1999, 712) \\
\hline kvota & $\begin{array}{l}\text { razmjeran dio, iznos ili količina, koji otpada na što; broj birača; dopuštena količina } \\
\text { (Anić, Goldstein, 2000, 770) }\end{array}$ \\
\hline lista & popis, iskaz (Klaić, 1999, 810) \\
\hline memorandum & predstavka; kratka pisana obavijest, izvještaj, podsjetnik (Anić, Goldstein, 2000, 845) \\
\hline muzika & glazba (Klaić, 1999, 921) \\
\hline pompa & pretjeran vanjski sjaj (Anić, Goldstein, 2000, 1032) \\
\hline PR stručnjak & stručnjak za odnose s javnošću \\
\hline procedura & utvrđen, propisan ili tradicijom uglavljen niz radnji (Anić, Goldstein, 2000, 1053) \\
\hline skandal & nepriličan događaj koji predstavlja javnu sramotu (Anić, Goldstein, 2000, 1186) \\
\hline stolica & stolac \\
\hline stroj & aparat \\
\hline supermarket & trgovina, dućan \\
\hline svota & iznos \\
\hline šef stranke & predsjednik stranke \\
\hline špekulacija & nagađanje \\
\hline špica & vrhunac čega (Anić, Goldstein, 2000, 1254) \\
\hline švicarac & švicarski franak \\
\hline tretirati & postupati s kim; ponašati se prema kome (Anić, Goldstein, 2000, 1338) \\
\hline
\end{tabular}


Tablica 2. RTL: Leksička odstupanja: tuđice, posuđenice, usvojenice, anglizmi

\begin{tabular}{|c|c|}
\hline RTL Direkt & \\
\hline alergičar & osoba oboljela od alergije, osjetljiva na podražaje (Anić, Goldstein, 2000, 67) \\
\hline ambijent & atmosfera koja vlada; ukupnost predmeta; životna sredina, (Anić, Goldstein, 2000, 78) \\
\hline alternativa & dvije mogućnosti kao izbor (Anić, Goldstein, 2000, 75) \\
\hline angažman & obveza, ugovor, zauzetost (Klaić, 1999, 70) \\
\hline babe & bake, starice \\
\hline balans & ravnoteža \\
\hline blef & obmana, varka, prijevara (Anić, Goldstein, 2000, 186) \\
\hline de facto & zaista, doista, zbilja, stvarno (Klaić, 1999, 264) \\
\hline disperzija & raspršenje, rasap, rasipanje (Anić, Goldstein, 2000, 314) \\
\hline dominacija & prevlast, premoć, nadmoć (Anić, Goldstein, 2000, 324) \\
\hline duplo & dvostruko \\
\hline efekt & učinak \\
\hline efikasnost & učinkovitost \\
\hline egzekucija & provedba, izvršenje smrtne kazne (Anić, Goldstein, 2000, 355) \\
\hline ekskluzivan & isključiv, koji je isključivo za povlaštene, odabrane ili imućne (Anić, Goldstein, 2000, 363) \\
\hline ekstrakt & srž, sukus, iscjedina, izvadak, iscrpak, suština, jezgra, sažetak (Klaić, 1999, 362) \\
\hline faliti & nedostajati \\
\hline friško & svježe \\
\hline gazda & gospodar, vlasnik, posjednik, poslodavac (Anić, Goldstein, 2000, 478) \\
\hline haker & $\begin{array}{l}\text { obuzet programiranjem i komp. tehnologijom, upada u tuđe sustave (Anić, } \\
\text { Goldstein, 2000,514) }\end{array}$ \\
\hline ilegalac & onaj koji se bavi ilegalnim radom, onaj koji neprijavljen boravi (Anić, Glodstein, 2000, 581) \\
\hline ilegalan & nezakonit; koji je protivan zakonu (Anić, Goldstein, 2000, 581) \\
\hline in & biti u toku sa čime, bit u obaviješten, biti u modi (Anić, Goldstein, 2000, 589) \\
\hline incident & nepredviđen događaj, nemio slučaj, izgred (Anić, Goldstein, 2000, 590) \\
\hline inspekcija & nadgledanje rada, nadzor, pregled, kontrola (Anić, Goldstein, 2000, 605) \\
\hline kljukati tabletama & uzimati, piti (tablete) \\
\hline kombinacija & slaganje, sklop, spoj, sjedinjenje (Anić, Goldstein, 2000, 706) \\
\hline komisija & povjerenstvo (Anić, Goldstein, 2000, 708) \\
\hline kompletno & cjelovito, cijelo, čitavo, potpuno (Anić, Goldstein, 2000, 711) \\
\hline konkretno & predmetno, opipljivo, određeno, usmjereno (Anić, Goldstein, 2000, 721) \\
\hline konsterniranost & preneraženost, zabezeknutost, zanijemjelost (Anić, Goldstein, 2000, 724) \\
\hline konverzija & zamjena jedne vrijednosti valute drugom (Anić, Goldstein, 2000, 731) \\
\hline krkljanac & gužva, zbrka \\
\hline kurikulum & kurikul \\
\hline
\end{tabular}




\begin{tabular}{|c|c|}
\hline likvidirati & smaknuti, ubiti (Anić, Goldstein, 2000, 792) \\
\hline lista & popis, iskaz (Klaić, 1999., 810) \\
\hline ljuti (čovjek) & ljutiti \\
\hline mail & elektronička pošta \\
\hline muzički & glazbeni \\
\hline on-line & priključen, izravno povezan s računalom (Anić, Goldstein, 2000, 939) \\
\hline općinari & djelatnici općine \\
\hline par & nekoliko \\
\hline parola & lozinka, geslo, krilatica (Klaić, 1999, 1012) \\
\hline pauza & stanka, odmor, počivka, prekid (Anić, Goldstein, 2000, 987) \\
\hline pazar & kupovina i prodaja, trgovanje, promet robe (Anić, Goldstein, 2000, 988) \\
\hline pilula & tableta, dražeja (Klaić, 1999, 1045) \\
\hline ponovo & ponovno \\
\hline porcija & dio, udio, obrok, komad (Klaić, 1999, 1070) \\
\hline pumpaš & djelatnik benzinske crpke \\
\hline radijus & polumjer, udaljenost neke točke od središta (Klaić, 1999, 1124) \\
\hline rampa & pregrada na želježničkim ili graničnim prijelazima \\
\hline rata & obrok otplate \\
\hline režim & način, stil vladanja; sustav pravila, propisa (Anić, Goldstein, 2000, 1124) \\
\hline siesta & podnevni počinak, spavanje poslije objeda (Klaić, 1999, 1221) \\
\hline sinkronizacija & usklađivanje, istodobnost, vremensko podudaranje (Klaić, 1999, 1231) \\
\hline specijalno & posebno, osobito, naročito, potanko, pobliže (Klaić, 1999, 1254) \\
\hline sprdati, sprdnja & rugati \\
\hline stacioniran & postavljen, smješten (Anić, Goldstein, 2000, 1208) \\
\hline summit & sastanak na vrhu \\
\hline super & izvrstan, odličan, najbolji (Anić, Goldstein, 2000, 1227) \\
\hline svita & pratioci istaknute osobe; pratnja (Anić, Goldstein, 2000, 1231) \\
\hline špica & vrhunac čega (Anić, Goldstein, 2000, 1254) \\
\hline štih & prepoznatljivo svojstvo kao dio ukupnosti svojstava (Anić, Goldstein, 2000, 1261) \\
\hline švicarac & švicarski franak \\
\hline tabla & ploča (Anić, Goldstein, 2000, 1271) \\
\hline tandem & $\begin{array}{l}\text { dvije osobe koje složno rade (Anić, Goldstein, 2000, 1280); sprega, savez, ortakluk za } \\
\text { izvršenje zadatka (Klaić, 1999., 1324) }\end{array}$ \\
\hline $\operatorname{tank}$ & cisterna, rezervoar ili bazen za benzin, ulje (Anić, Goldstein, 2000, 1282) \\
\hline trend & tendencija prema čemu, smjer razvoja (Anić, Goldstein, 2000, 1338) \\
\hline tron & vladarska stolica; prijestolje; čast i moć (Anić, Goldstein, 2000, 1347) \\
\hline vintage & berba vina \\
\hline
\end{tabular}




\title{
Transmedia functions of stylistic figures in film and lexical abberations in the news TV shows
}

\author{
SUNČANA TUKSAR, PhD \\ Juraj Dobrila University of Pula
}

IRENA OSTRIČKI GERBER, mag. bibl. et mag. educ. philol. croat.

PhD Candidate, The Doctoral School of Josip Juraj Strossmayer University of Osijek

When it comes to communicative functions of the media, nowadays it is almost impossible to investigate such functions in a globally connected society without taking into further account their transmedial nature. Drawing from the sociosemiotic analysis this paper investigates some functions of lexical aberrations in both Croatian and English, as well as in television and film. The aim of the paper is primarily to show how lexical aberrations in English (slang) in Jim Jarmusch's film Night on Earth (1991) establish cultural concepts and point towards the acknowledgement of intercultural competences. Also, the analysis encompasses the role of Anglicisms in the Croatian language in both public and commercial televisions. Joint analyses point towards a further sociolinguistic argument about linguistic literacy in the media, but also towards a fact that the lexical aberrations are of extreme importance regarding visual and media literacy in a global culture. The relationship between mass media and language is not only the reference to their intrinsic communicative traits but also a vivid reminder of constant intertwining of the humanistic and social area.

Key words: Transmediality, globalisation, language aberrations, culture 